\title{
Designing Integrated Information Systems for Health, Nutrition and Population Sector Programs in Bangladesh : A Model Plan
}

\author{
Md. Saiful Alam, $P h D^{*}$
}

\section{Introduction}

A workable information system is one of the essential programmatic needs for the Health, Nutrition and Population (HNP) sector programs in Bangladesh. At present, Ministry of Health and Family Welfare is maintaining hierarchical reporting system called Management Information System (MIS) for assessing, evaluating and monitoring its health, nutrition and population sector programs. It has undergone several changes and modifications over the last three decades since its inception in 1975. In response to the needs for evidence-based decision making and enabling the system to deliver timely reliable information to the planners, managers and professionals, government has taken significant initiatives for improvement of information systems at all levels of the sector. However, due to the bifurcated structure in the Ministry of Health and Family Welfare (MOHFW), adequate and timely monitoring of sector performance is not yet a reality and the culture of using information for decision-making has not yet taken roots. Duplication of services, delay in placing manpower, equipment etc. still reduce the possibility to make facilities fully functional. Insufficient coordination between various sub-sectors in health, population and nutrition resulted in duplication, wastage and missed opportunities both at the top as well as at the operational level. Though MOHFW has been in the process of developing a routine data system, the MIS has been severely criticized for its narrow coverage, faulty output, under utilization of data, etc. Similarly, no

\footnotetext{
*Associate Professor, Department of Information Science and Library Management, University of Dhaka.
} 
initiative has been taken to develop proper library and information systems let alone the integration of library system and MIS. Considering the socio-economic, technical, infrastructural, policy and administrative issues of the country, the design of an integrated information system is the main focus of the study.

\section{HNP Programs in Bangladesh}

HNP services are also fundamental rights of the people. Constitutionally (according to articles 15(a) and 18(1), the Government of Bangladesh is obligated to ensure provision of basic necessities of life including medical care to its citizens and to raise the level of nutrition and to improve public health. Bangladesh has been implementing sector-wide approach (SWAp) in health sector since 1998. The first SWAp - the Health and Population Sector Program (HPSP) - was implemented during 1998-2003 (MOHFW 1998: 48). The program currently under implementation is the Health, Nutrition and Population Sector Program (HNPSP) for 2003-2011. The next sector program will be implemented from July 2011 onwards, without any interruption between the current and next sector program. The framework of the proposed health sector program from July 2011 to June 2016 is set against the broader perspective of the GOB's commitments (Constitution, MDGs, Vision 2021, the proposed National Health Policy and the National Population Policy) and other programs, policies and strategies including the National Strategy for Accelerated Poverty Reduction II. The health sector is actively involved in the preparation of the government's Sixth Five Year Plan (SFYP) for 2012- 2016 (MOHFW 2010: 4).

The first SWAp (HPSP) marked a shift from a multiple project approach to a single sector program. The new Health Sector Program sets out several 'drivers' for achieving the 5 year goal. The seventh component aims at strengthening the overall health system with a 'Health Information System (HIS). The program components are categorized into three components. These are:

1. Component 1- Improving Health Service Delivery

2. Component 2 - Strengthening Health Systems

3. Component 3 Stewardship and Governance. 
Under component 1, the program will support (i) Delivery of essential health services which seek to improve reproductive, maternal, neo-natal and child health, (ii) Reduce TFR with increased use of long-term family planning methods, (iii) Prevention, control and management of communicable and noncommunicable diseases, (iv) Mainstream essential nutritional services, especially of pregnant women and children, and (v) Increase access to and use of the essential health services.

Under component 2, the program will strengthen the various health systems, required to implement effectively the various service delivery activities. In this document they are identified as (i) sector planning and budgeting, (ii) health information systems, monitoring / evaluation and research, (iii) human resources for health, (iv) financing of the health sector, (v) quality improvements, (vi) management of pharmaceuticals and supply chain management, (vii) procurement and (viii) physical facilities development and maintenance.

Under component 3, the program will address stewardship of the sector in the areas of (i) governance structures and the legal framework, (ii) sector policy development, reforms and issues of equity, gender and citizen's voice (ii) decentralization and Local Level Planning, (iii) partnerships and coordination, (iv) sector-wide approach, including aid effectiveness, (v) financial management in the health sector, and (vi) technical cooperation (MOHFW 2010: 8).

\section{Information Systems for HNP Sector}

As an information system, the Ministry of Health and Family Welfare has been maintaining hierarchical reporting system called MIS. Prior to that, a statistics compilation unit called 'Service Statistics Cell (SSC)' was founded in early 1975 (PDEU 1996: 1). During the Third Five Year Plan period the concept of SSC was abandoned and its resources were placed under the new project titled Strengthening of MIS unit' with a goal for establishing a regular system of data collection and analysis of performance statistics received from all over the country. Accordingly, MIS began to collect the service statistics on contraceptive service delivery, particularly distribution of oral pills, condoms and a 
number of sterilizations performed and IUD inserted, and produce monthly report from the year 1980 (Choudhuri 1989: 5). Up to 1989 different initiatives were taken to establish a regular system of data collection and reporting through Directorate of Family Planning (DFP) and Directorate General of Health Services (DGHS). Since then two separate streams of information systems has been running by the two directorates.

In a survey carried out by MIS professionals in one of the districts, an assessment was made of the types of services provided under RH/FP as well as the existing recording and reporting tools. The findings indicated that data were being collected in the field from 145 types of $\mathrm{MCH}-\mathrm{FP}$ and $\mathrm{RH}$ care services. According to a study, data were gleaned at the field level from 145 types of $\mathrm{MCH}-$ FP and RH care services using 45 registers, 17 cards. In addition, 26 types of reporting forms were being used by the different offices and service delivery points in the public, NGO and private sectors (Ahmed 1999: 2).

In July 1998, as a consequence of the reform and remodeling of FP and health services, HPSP has recognized a unified MIS as one of the essential support services. In the logframe it has been defined as "Unified, sector-wide, need based data system able to collect, analyze and use data for planning and management purposes at relevant level" (MOHFW 1998: 3). However the project was ended without any successful implementation. According to DGFP, FP program under HPSP was an unsuccessful attempt: "Unfortunately, the family planning program during HPSP under the unified structure at the upazila and below level contributed to a loss of momentum in RH-FP service delivery, and the program became almost paralyzed" (Directorate of Family Planning 2006). However, the government upon review, decided in January 2003 to reestablish separate organizational structures and authority for health and family planning and the new structure is HNPSP. Health, Nutrition and Population Sector Program (HNPSP) is running under Strategic Investment Plan 2003-2010 through a sector wide approach. This approach is going to be extended from July 2011 in the Sixth Five Year Plan (SFYP) for 2012- 2016. As before 1998 the HNPSP MIS has been functioning under two separate streams independently: MIS of 
DGHS and MIS unit of DGFP. FP MIS have reintroduced the FWA register and house visitation by the FWAs and started publishing monthly report. The addition to the HNPSP in the sixth five year plan will be the introduction of a Health Information System (HIS) having a broader view to capture all the agencies of the ministry. In the HNP sector strategic plan it has been defined as "All the data and records about the population's health, which uses recording of births, deaths and causes of death, and other vital events (marriage, divorce, adoption, legitimating, recognition of parenthood, annulment of marriage, etc.) censuses and surveys, individual medical records, service records, and financial and resource tracking information as the data sources" (MOHFW 2010: 65).

In the past information systems related activities were not given due attention in the health and population program in Bangladesh. According to different literature it is evident that former MIS programs up to 1998 of the Directorate General of Health Services (DGHS) and Directorate General of Family Planning (DGFP) were ended due to a lot of inconsistencies including narrow coverage, errors in data capturing, forms and procedures, reporting, duplication of efforts, lack of co-ordination and control among the field workers etc. Next initiative for establishing Unified MIS that has aimed at eliminating the former inconsistencies and broadening its scope with programmatic needs of HPSP has also been paralyzed with ending of HPSP project in 2003. Now the scope health and population program has widened further and has included national nutrition program with in the framework of HNPSP. Though HNPSP MIS is functioning as before 1998 under two separate streams independently: MIS of DGHS and MIS unit of DGFP, no serious initiative has been taken yet to check the validity and workability of the reintroduced FWA register and other forms and procedures' at the field levels. The system has yet not been able to eliminate the inconsistencies as they were before 1998 .

According to WHO guidelines information obtainable through a Health and Population Information System (HPIS) may be usefully categorized into the some interrelated and possibly overlapping sub-systems: Epidemiological surveillance (e.g. disease 
case and outbreak notifications); Service records and reporting (from community health workers and health care delivery facilities); Program monitoring and evaluation (for example, specific for TB, MCH/FP, EPI, etc.); Administration and resource management information systems (e.g. budget, personnel, logistics, etc.); Vital registration (e.g. births and deaths) (WHO 2006: 7). But the existing structure of the health and population sector information system does not cover all these aspects; rather it has attempted to include the service statistics from different service delivery points in the health and family planning programs. An attempt has been made to include logistics management, personnel management, financial management, epidemiological surveillance data system in the earlier UMIS. Ultimately, those efforts have been terminated without any fruitful end. The necessity of a knowledgebase for the research and decision support in the said sector is still an outside issue. Not only that, practicing librarians and information centers have no functional relationship with the MIS systems. An attempt has been made in the study to design an integrated information system in which integrated MIS and libraries will work under the same umbrella.

\section{The Model Plan}

Considering the colossal gap between information needs and existing information services, it becomes urgent to build an integrated information system for programmatic and research support in the health, nutrition and population sector programs in Bangladesh. The system may be denoted as "The National Health, Nutrition and Population Information Center (NHNPIC)" that will ideally be a comprehensive knowledge-based system capable of providing information and references to all in the concerned sectors. As a whole, the NHNNPIC will be known as the common space where health and population information sources are traced, organized, indexed, preserved, accessed and evaluated. It should have a decentralized networked management of health and population knowledge sources and flows that will influence the country-wide information seeking behavior in the said sector. This model will outline a vision, test the feasibility and design considering no major changes in the administrative and policy factors. It will also look into the process of mobilizing the existing 
resources, institutional capacity building and technological factors needed to design a national health nutrition and population information center.

\section{Objectives}

The prime objective of the proposed information system will be to provide access to information and scientific, technical and factual knowledge on health, population and related disciplines. The NHNNPIC will include the values, practices, relationships, laws, standards, systems, applications, and technologies that support all facets for free flow of information in the health nutrition and population sector in Bangladesh. More specifically the NHNNPIC aims at:

i. Bibliographic control on the published and unpublished literature as well as link to external resources (preferably web resources) on health, population, nutrition and allied subjects;

ii. Developing a sound collection for comprehensive study and research for the said disciplines;

iii. Developing a central databank for text and metadata, directory of hospitals, clinics and physicians; statistical data and reports of MIS etc.

iv. Sharing ICT, human resources as well as knowledge and skills among the participating libraries and information centers;

v. Ensuring users online access to query processing and retrieval from digital resources in a web server-browser environment.

\section{System Architecture}

Considering the existing administrative structure of the MOHFW health and population program, four layers of administrative structure as a hierarchical pyramid may be suggested for the proposed information system- NHNNPIC: The layers will be: 


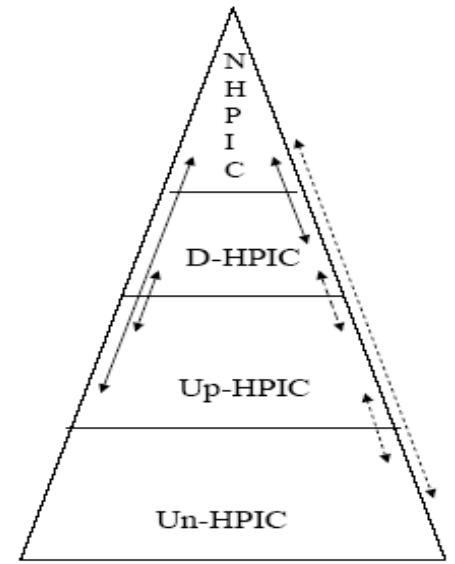

Figure 1: NHNNPIC

The N-HPIC at the national level

a) The D-HPIC (District Health and Population Information Center) at the district level.

b) The Up-HPIC (Upazilla Health and Population Information Center) at the rural upazila level and

c) The Un-HPIC (Union Health and Population Information Center) under the coordination of FWV (Family Welfare Visitor) at the UHFWC (Union Health and Family Welfare Center) at the union level.

The NHNNPIC will work at the central level under the direct coordination of the Ministry of Health and Family Welfare (MOHFW). The administration of health and family planning programs are of two separate streams: DGHS and DGFP. On the other hand, hospitals, public health, gender issues, libraries are administrated by separate Deputy Secretary (DS) of MOHFW. So for better coordination and control, the information center should be administrated by an additional secretary or by the joint secretary of coordination. The NHNNPIC will be the apex body and concerned directorates, departments and others organizations will participate both as contributing and beneficiary nodes. Some possible nodes are: DGHS with MIS Department and NHLDC; DGFP with MIS Department and NIPORT; Directorate of Nutrition Services (DNS) with concerned departments; Department of Drug Administration (DDA); DSs of hospital services, public health, gender issues etc. There should be some other participating nodes outside the MOHFW. These are: NGO Bureau, Ministry of Education/Department of medical education, research institutes on medical sciences and local offices of some international organizations such as UNFPA, UNDP, UNICEF, and so on. 


\section{Equipment and Infrastructure}

Ideally, the set up of the NHNNPIC will be technology based. All departments and working sections of the NHNNPIC (central office to rural UHFWC) will be quipped with necessary computing communication facilities. At the central office there will be a dedicated LAN server responsible for total network management and information sharing among the functional units. The acquisition department should have online access to publishers and vendor's catalog, ability to receive online request from the remote users, upload and downloading facilities. The digitization and reprographic section should be equipped with high speed digital scanner, printer, CD/DVD writing facilities photocopier, and microform equipment. To ensure circulation system and inventory, the desk computer and computers at the reading room and reference section must be connected to the central data server with necessary privileges. To connect the central server from the rural UHFWC, they have to dial up through cell phone which is very difficult. Each UHFWC should have a computer for MIS data collection, compilation and manipulation under a professional information worker. If the communication facilities improve, particularly connected with optical fiber backbone network, the information resources can be mobilized from center to the grass-root level in an easy and cost effective way in near future.

\section{The NHNNPIC Sub-systems}

Considering the nature of the NHNNPIC, the information system can be decomposed into two sub-systems: a) knowledge system and b) MIS. Each sub-systems will be consisted of more than one logical sub-sub-systems or working modules. The knowledge system will include acquisition, processing, circulation, reference, digitization and online services sub-modules. The MIS subsystem will include statistics of essential service package, a) Logistic management (LMIS), b) Personnel management (PMIS), c) Financial management (FMIS), and d) Epidemiological surveillance (EMIS). Besides this routine service statistics, the NHNNPIC MIS sub-system will include some additional modules e.g. household survey, birth registration, disease surveillance, census, behavioral risk surveys etc. 
Figure 2: NHNNPIC sub-systems

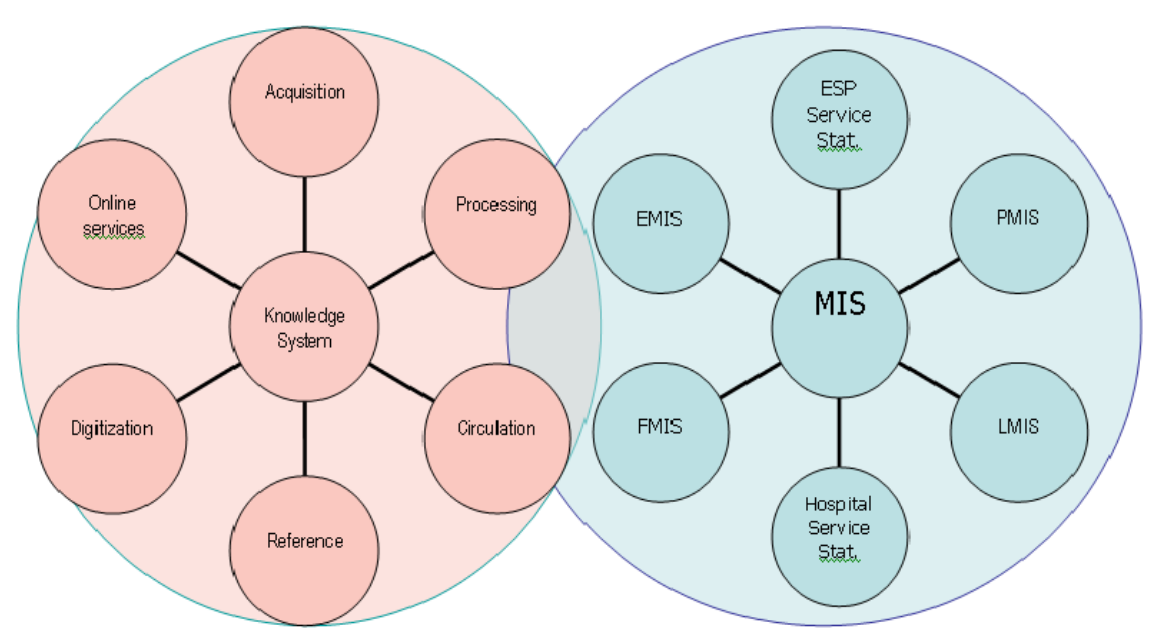

\section{System Input and Output}

The input data for the central database will include:

i. Bibliographical data and other metadata: This category includes data about the description of the data/information sources e.g. books, articles of journals, news clippings, users, etc.

ii. PDF electronic document: the NHNNPIC will store all e-books, e-journal and scanned and OCR documents as acrobat PDF (Portable File Format). The bibliographical description will be at the database with a link field to the pdf file so that each bibliographical item can be accessed with full text from the Internet browser.

iii. HTML objects: user-system interaction will be supported with HTML at the web server. Client-server communication, sending request for books and journals, document, notification of user and systems, user profile sending and periodic update, commentary, discussion, e-seminar and conferences, etc. will be available on the Internet as html file.

iv. MIS data: The main data sources for MIS are household, community clinics, Union Health and Family Welfare Center at the rural villages and union level, Upazila Health Complex 
(UHC) and Thana FP office at the upazila level, District Hospitals and Maternal and Child Welfare Center (MCWC) at the district level. At present, the data collection system comprised a set of nine types of forms, registers, slips, and cards.

\section{System Requirements}

Being a nation wide integrated information system the NHNNPIC warrants some basic requirements for its successful design and implementation. The system will be committed to maximize the use of existing resources. The system requirements of NHNNPIC will include some policy decisions, equipments and infrastructural facilities available in the country. The new system requirement and feasibility has been outlined below.

i. There must be a policy decision by the government that the information system for the existing health, population and nutrition sector will be integrated and the system must have the capability to meet the knowledge, strategic, management and operation level information needs.

ii. All participating member organizations should have a decision that all information related activities should be library and information center oriented, not scattered.

iii. An optical fiber backbone with a common gateway/proxy with several servers such as data server, directory server, web/http server, ftp server.

iv. Sufficient number of networked computers with necessary printing, backup and other accessories for the NHNNPIC central office.

v. At least one high speed scanner for the digitization at the central office of NHNNPIC

vi. At least one computer at the lowest level of the proposed information system at the union level UNHNNPIC; three computers at the upazila level UpHPIC and five at the DHPIC. The DHPIC and UpHPIC must have dial-up/Wireless network access to the web server of NHNNPIC. 
vii. There should be a VSAT (Very Small Aperture Terminal) with necessary bandwidth to ensure connectivity and smooth transmission of data among the network members.

viii. Each participating member library or information center must have at least one computer with printing, scanning and communication facilities to connect the central proxy server.

ix. At least one photocopier and a CD-RW/Combo drive for necessary data back-up and reproduction.

X. Standard software supports.

\section{Implementation}

Implementation involves hardware, software, procedure, and human-ware of the new system to the operational stage. To implement the proposed NHNNPIC, the following activities are to be accomplished, step by step:

i. After formulating the necessary policy and decision, participating members should sit together to formulate network agreements, cooperative acquisition and distribution policy, library standard, circulation and inter-library loan procedures and other legal issues should be formulated.

ii. Each participating organization/library shall have to be designated as information center for a particular subject or discipline in which it may build up its unique collection. It would concentrate on its core subject. The remaining peripheral subjects may be taken by other institutes where such subjects form the core collection. This needs a detailed survey of collection and its use.

iii. Setting the data collection procedures from rural community clinics, satellite clinics, and UHFWC, and sending the data to UHC. The UpHPIS will enter the data to the prescribed database and send the data file to the central NHNNPIC.

iv. Programming the systems according to the set flowchart, decision tables, description of inputs, outputs and files, and specification of each procedure, configure and host the web server 
v. Each member of the network will prepare bibliographical entries according to the prescribed format and will send it to the central database online. If the participating library can use card form of catalog, they can print card catalog for their internal use. The central data bank will upgrade the data file periodically and publish union catalog.

vi. Testing and debugging program.

vii. Final Implementation of the system that includes the followings:

$>$ Installation of necessary hardware resources

$>$ Installation of software /program

$>$ Appointing human resources

$>$ Training of the personnel

$>$ Prepare any documentation

$>$ Running the system and coordinate the functioning

$>$ Perform follow up and review the evaluation process

\section{Conclusion}

The proposed National Health and Population Information Center (NHPIC) may work as a sketch for establishing a need based system that will ensure free flow of information from the policy level to the extreme end of implementation of HNPSP. During design of the system due attention has been paid to the socioeconomic, technical, financial, infrastructural, policy and administrative issues of the country. Thus, the system is expected to be realistic in information system for the HNPSP in Bangladesh. Every plan has a 'movable horizon', i.e. it is never definitive but can and should be improved in the light of experience, and will inevitably have to be adapted to the changing situation. It is important, therefore, that the plan should include the provision for evaluation and amendment as and when necessary. 


\section{References}

Ahmed, T. "Monitoring Reproductive Health: Bangladesh" in Asian Population Studies Series. http://www.unescap.org/pop/publicat/apss155.htm.accessed on July 2007

Choudhuri, S. R. 1998. Management information system in the family planning, in Proceedings of regional workshop on population training institutes management. Comilla: BARD

Directorate of Family Planning. Family Planning programs in Bangladesh Dhaka: DFP. www.dgfpa.gov.bd_English accessed on 15 September 2008

Ministry of Health and Family Welfare. 2010. Health Population \& Nutrition Sector Strategic Plan (HPNSSP) 2011-2016-Dhaka: Planning Division

Ministry of Health and Family Welfare (MOHFW). 2003. Health, Nutrition and Population Sector Program (HNPSP) 2003-2006: program implementation plan. Dhaka: MOHFW

Ministry of Health and Family Welfare (MOHFW). 1998. Health and Population Sector Program (HPSP): program implementation plan, part1. Dhaka: MOHFW

Population Development and Evaluation Unit (PDEU). 1996. Management Information System in the Bangladesh National Family Planning Program: an Assessment of Strengths and Weaknesses of Service Statistics. Dhaka : Ministry of Planning.

World Health Organization. 2006. Issues in health information system: national and sub-national health information system, Geneva : WHO, Health Metrics Network (HMN) 